\title{
Attract and deter: a dual role for pyrrolizidine alkaloids in plant-insect interactions
}

\author{
Mirka Macel
}

Received: 16 January 2010/ Accepted: 21 April 2010/Published online: 8 May 2010

(C) The Author(s) 2010. This article is published with open access at Springerlink.com

\begin{abstract}
Pyrrolizidine alkaloids (PAs) are the major defense compounds of plants in the Senecio genus. Here I will review the effects of PAs in Senecio on the preference and performance of specialist and generalist insect herbivores. Specialist herbivores have evolved adaptation to PAs in their host plant. They can use the alkaloids as cue to find their host plant and often they sequester PAs for their own defense against predators. Generalists, on the other hand, can be deterred by PAs. PAs can also affect survival of generalist herbivores. Usually generalist insects avoid feeding on young Senecio leaves, which contain a high concentration of alkaloids. Structurally related PAs can differ in their effects on insect herbivores, some are more toxic than others. The differences in effects of PAs on specialist and generalists could lead to opposing selection on PAs, which may maintain the genetic diversity in PA concentration and composition in Senecio species.
\end{abstract}

Keywords Evolution - Performance ·

Preference $\cdot$ Tyria jacobaeae $\cdot$ Jacobaea vulgaris

M. Macel $(\square)$

Department of Terrestrial Ecology, Netherlands Institute of Ecology (NIOO-KNAW), Boterhoeksestraat 48, 6666 GA Heteren, The Netherlands

e-mail:m.macel@nioo.knaw.nl

\section{Introduction}

Pyrrolizidine alkaloids (PAs) are constitutive plant defenses against herbivores. They are present in several different plant species, amongst which the genera Eupatorium (Asteraceae), Crotolaria (Fabaceae), and Senecio (Asteraceae) (Hartmann 1999). These secondary plant compounds are infamous for their hepatotoxic and pneumotoxic effects on some mammals, like cows and horses. Cattle can contract alkaloid poisoning primarily through the consumption of hay poisoned with Senecio material (Mattocks 1986; Cheeke 1988). The livers of mammals can be severely damaged by toxic pyrrols, the breakdown products of PAs that are formed in the gut (Mattocks 1986). In the field, mammals generally avoid PA-containing plants of the Senecio genus. The role of the alkaloids in Senecio as defense against mammalian herbivores seems therefore unequivocal. Their role in the defense against insects, however, is less straightforward. Unlike most mammals, insect herbivores are more selective feeders. The majority of insects are specialized feeders of some sort, specializing on particular plant species, genera or families or on particular plant organs. The varying degree of host plant specialization in insects has led to different ways of insects to deal with and respond to plant secondary compounds (Deprés et al. 2007). Some of the specialist insect herbivores with a narrow host range have evolved physiological adaptations to the specific secondary metabolites in their host plants 
(Aplin and Rotschild 1972; Naumann et al. 2002; Wittstock et al. 2004). They often even use these compounds to find their host plant and use these chemicals for their own defense. On the other hand, generalist herbivores that feed from many different plant species may be less adapted and could be negatively affected by plant secondary compounds.

Here I will review the different ways that insect herbivores cope with PAs of the plant genus Senecio, as well as their behavioral response to these compounds. There is a list of around 40 insect herbivores found on the PA-containing Senecio jacobaea (Harper and Wood 1957). Some of those insect herbivores, like the cinnabar moth Tyria jacobaeae and the flea beetle Longitarsus jacobaeae, feed exclusively on Senecio jacobaea and close relatives. Others, like Arctia caja, feed on PA-containing plants from different genera. There are also some insect herbivores that feed from all kinds of plants, regardless of their plant secondary compounds. Thus, the diet breath of the insects on Senecio is rather diverse which reflects in the ways they deal with PAs.

The structure of PAs is important for their activity to insects. PAs in Senecio are of the senecionine type (Hartmann and Witte 1995) (Fig. 1). The backbone structure of most PAs in Senecio species is senecionine $\mathrm{N}$-oxide. Other PAs that occur in Senecio, such as seneciphylline, jacobine, and senkirkine are all derived from senecionine (Fig. 1) (Hartmann and Dierich 1998). There is a great diversity of PAs within Senecio species. Each species usually contains multiple PAs and has a species-specific PA pattern (Hartmann and Witte 1995). In addition, also within species different PA chemotypes can be found (Witte et al. 1992). PAs are not induced in shoots after herbivory (Van Dam et al. 1993; Hol et al. 2004) but they are induced in the roots when roots are damaged (Hol et al. 2004). PAs can occur in two forms, the tertiary free base and the $\mathrm{N}$-oxide. Both forms are present in plants (Joosten et al. 2009). In the roots, the PAs were almost exclusively present as $N$-oxides and not as free bases while in the shoots around $35 \%$ of the PAs were tertiary free bases. The $N$-oxide can be broken down to the tertiary PA in the gut of insects and mammals, where it is absorbed and further reduced to highly unstable toxic pyrrols. The PA $N$-oxide itself, which is non-toxic per se, cannot be directly converted into toxic pyrrols and is hydrophylic and unable to passively pass through membranes (Hartmann 1999).

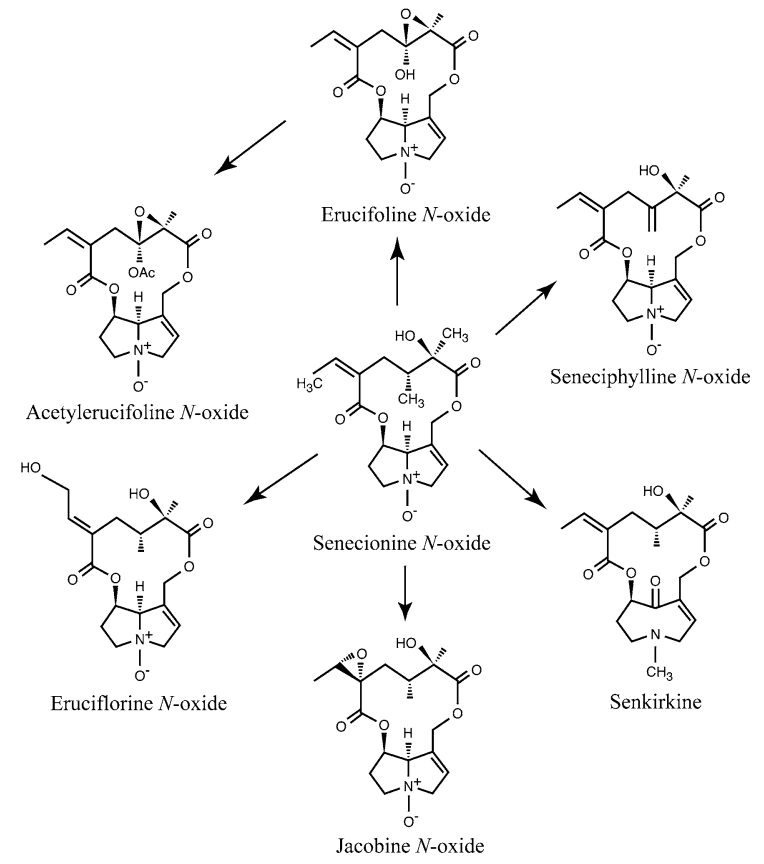

Fig. 1 Examples of PAs found in Senecio species. Senecionine $N$-oxide is the basic structure from which other PAs are formed. These senecionine type PAs have an otonecine (senkirkine) or retronecine ester base (e.g., senecionine) and a 12-membered macro-cyclic ring. Drawings: Martin Brittijn

\section{Effects of PAs on specialized insects}

Metabolism of PAs

Some specialized insects are able to detoxify PAs in their host plant through $\mathrm{N}$-oxidation (Lindigkeit et al. 1997; Naumann et al. 2002). By $N$-oxidation potentially toxic free bases are converted back into PA $\mathrm{N}$-oxides that cannot be transformed into toxic pyrrolic derivatives (Hartmann 1999). For the specialist Tyria jacobaeae (Fig. 2), feeding on S. jacobaea and related Senecio species, the detoxification mechanism is well studied. This moth species efficiently $\mathrm{N}$-oxidizes the PAs in the haemolymph with the enzyme senecionine $N$-oxygenase (SNO), which is a flavin-dependent monooxygenase (Lindigkeit et al. 1997; Naumann et al. 2002). Similar to detoxification mechanisms of insects in other systems, the enzymes involved are of the P450 family (Naumann et al. 2002; Li et al. 2003; Wittstock et al. 2004). These P450 enzymes occur in all kingdoms of life and are amongst others involved in the xenobiotic metabolism of an organism. In specialized insects, 

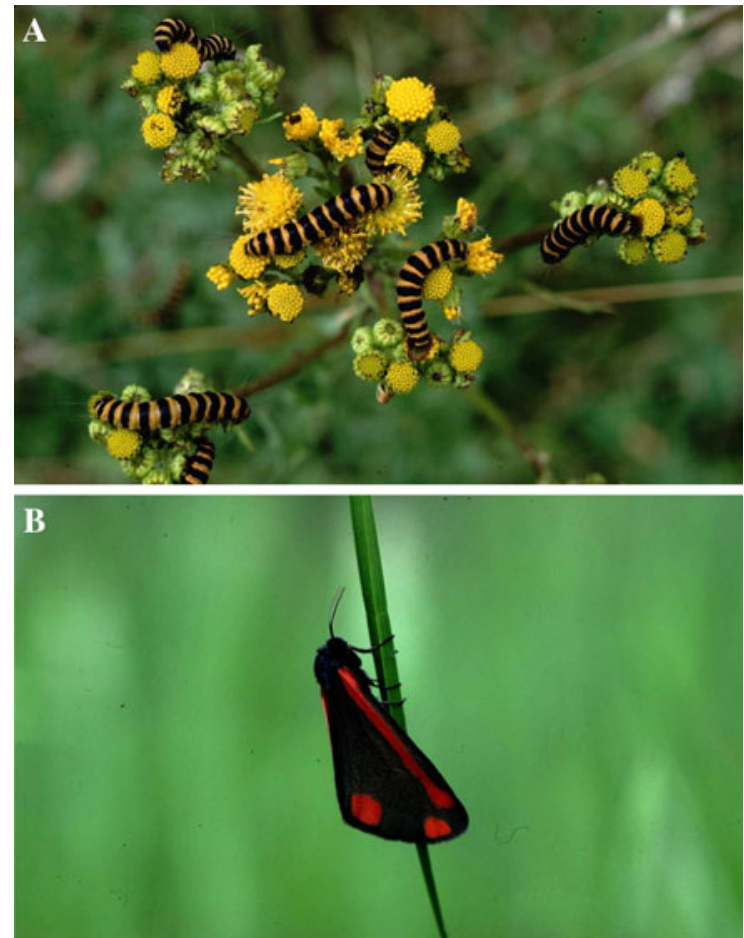

Fig. 2 a Larvae of the specialist moth Tyria jacobaeae feeding on their host plant Senecio jacobaea, b adult T. jacobaeae. Both larvae and adults contain pyrrolizidine alkaloids and show aposematic warning coloring. Photo's: Eric Thomassen

P450 enzymes have evolved to detoxify specific metabolites (Deprés et al. 2007). The SNO in T. jacobaeae is highly specific to pyrrolizidine alkaloids. Its activity is highest on senecionine type PAs which occur in the host plant $S$. jacobaea, other types of PAs are less well converted (Lindigkeit et al. 1997; Naumann et al. 2002). Specialist Longitarsus flea beetles (Chrysomelidae) can also $N$-oxidize tertiary PAs (Naberhaus et al. 2003). The enzymes involved are unidentified but are likely also P450s. SNO was also found in other insects such as the arctiid moths Creatonotos transiens and Arctia caja. Both moth species have a wider host range than Tyria and feed from multiple plant genera (PA adapted generalists). The SNO from C. transiens and A. caja has a broader substrate affinity than the SNO from Tyria (Lindigkeit et al. 1997).

Specialist insect herbivores but also PA adapted generalists may even sequester PAs for their own defense (Rothschild et al. 1979; Von NickischRosenegk and Wink 1993; Dobler 2001; Pasteels et al. 2003; Naberhaus et al. 2003). Larvae of T. jacobaeae store PAs from their host plants primarily in their haemolymph and the integument. In fact, all life stages of $T$. jacobaeae contain PAs; eggs, larval, pupae and adults (Van Zoelen and Van der Meijden 1991). Several arctiid moths, like T. jacobaeae and Arctia caja, also transform plant acquired PAs into insect specific PAs like callimorphine (Aplin and Rothschild 1972; Ehmke et al. 1990; Hartmann 1999). Longitarsus flea beetles also sequester PAs (Dobler 2001; Naberhaus et al. 2003). PAs are sequestered as $N$-oxides (Hartmann 1999) and the concentrations of PAs in insects can exceed the concentrations in plants (Aplin and Rotschild 1972). The sequestered PAs protect the arctiid moth Utetheisa ornatrix, which feeds from PA containing Crotolaria species, against predators (Eisner and Eisner 1991). PAs can thus affect the preference and performance of the third (and higher) trophic levels (see a review by Trigo in this issue). PA sequestration is not solely limited to specialists within the arctiids and chrysomelid families. Some danaine and ithomiine butterflies, ctenuchiid moths and the African grasshopper Zonocerus variegatus also sequester PAs (Boppré 1986; Nishida 2002). Not all PA adapted insects acquire PAs from larval host plants. Adults may also obtain PAs pharmacophagously from withered and decomposing plants or PA containing nectar (Boppré 1986). Some PA adapted insects use the alkaloids as pheromone precursors and PAs can be transferred from males to females during mating (for reviews see Hartmann 1999; Nishida 2002). Most, if not all PA sequestering insects show aposematic warning coloration (Hartmann 1999).

Effects of PAs on specialist preference and performance

The physiological adaptations to PAs and their ability to sequester these compounds, suggests that specialist insects may even depend on PAs to find their host plants. Bioassays using isolated PAs showed that T. jacobaeae indeed uses PAs as oviposition cue. Not all PAs stimulated oviposition; while senecionine, seneciphylline and monocrotaline were attractive, retrorsine, senkirkine, and heliotrine were not stimulatory (Macel and Vrieling 2003). Surprisingly a mixture of alkaloids for a non-host plant (Senecio inaequidens) was equally attractive as a PA mixture 
from S. jacobaea (Macel and Vrieling 2003). The danaid butterfly Idea leuconoe, a specialist on Parsonia laevigata (Apocynaceae), can also use the PAs in its host plant as oviposition stimuli (Honda et al. 1997). Besides Tyria, it is unknown if other specialists on Senecio use PAs to find their hosts. Larvae of $T$. jacobaeae have PA specific taste receptors (Bernays et al. 2004). However, caterpillars will only feed from Senecio leaves and will not accept any neutral substrates such as lettuce disks and artificial diets with added alkaloids (Macel unpublished data), indicating that other factors are needed to stimulate feeding in Tyria. Similar PA specific taste receptors have been found in other arctiid moths that feed on PA containing plants, such as the specialists $U$. ornatrix, and PA adapted generalists Estigmene acrea and Grammia geneura (Bernays et al. 2002a, b, 2003). Utetheisa ornatrix larvae preferred artificial diets with PAs to diets without PAs (Kelley et al. 2002) which indicates that PAs stimulate feeding in this species.

Despite the stimulatory effects of PAs on feeding and oviposition of adapted insects, correlations between specialist insect preference and PA concentration and profiles of Senecio plants are not always apparent. The diversity of PAs in Senecio species did not determine host plant preference of Tyria jacobaea (Macel et al. 2002). PA chemotype of S. jacobaea also did not affect preference of this specialist (Vrieling and de Boer 1999; Macel et al. 2002). In the field, total alkaloid concentration in S. jacobaea was not an important factor in selection of food plants for the cinnabar moth (Van der Meijden et al. 1989). Thus, although this specialist can clearly recognize PAs, the role of the alkaloids for host plant selection is less clear. Possibly, it uses PAs as a general cue to recognize its host plant amongst other plants species, but within the host plant species, selection depends on other factors such as nutrients (Van der Meijden et al. 1989). The relation between damage by the flea beetle Longitarsus jacobaeae and PA concentrations in plants ranged from positive to negative (Vrieling and van Wijk 1994; Stastny et al. 2005). These findings are all based on field studies where various factors can determine insect behavior, which could have masked any potential correlation between alkaloids and host preference. The presence of the specialist thrips Haplothrips senecionis was not correlated with PA concentration (Vrieling et al. 1991a). Senecio jacobaea plants infested with the specialist aphid Aphis jacobaeae had a lower alkaloid concentration than plants that were not infested by these aphids, which suggests that this specialist may be negatively affected by high PA concentrations. Here, however, the third trophic level could also have played a role in host plant selection. The ants tending these aphids would probably benefit from lower PA concentrations in the honeydew (Vrieling et al. 1991b).

Surprisingly little studies have investigated whether PAs affect specialist insect performance, i.e., survival, growth, development time and pupal weight. The PA seneciphylline added in artificial diets did not affect development of two specialist leaf beetles (Hägele and Rowell-Rahier 2000). Similar to its adult preference, the performance of the larvae of the cinnabar moth $T$. jacobaeae, measured as pupal weight and development time, was not affected by PA profile or concentration of the host plant (Vrieling and de Boer 1999; Macel et al. 2002). For other specialists on Senecio it is still largely unknown whether PAs affect performance.

\section{Effects of PAs on generalists}

Metabolism of PAs

Although the toxicity of PAs to mammals is extensively studied, the toxicity and the mode of action of PAs towards non-adapted generalist insects are less known. PAs are genotoxic and mutagenic to Drosophila melanogaster (Frei et al. 1992). The structure-activity relationship in Drosophila is similar to the effects of PAs on mammals, which suggest that the same mechanisms may be involved (Frei et al. 1992). The $\mathrm{LD}_{50}$ of PAs in mammals is partly determined by the presence and structure of the macrocyclic ring (Wink et al. 1998). The base of the PA is also important. PAs with an otonecine base (e.g., senkirkine) can have a different effect than PAs with a retronecine base (e.g., senecionine) (Fig. 1) (Frei et al. 1992). PAs are likely to be broken down to toxic pyrrols through P450 enzymes in the insect's gut (Hartmann 1999). Studies using ${ }^{14} \mathrm{C}$-labeled senecionine $N$-oxide showed that the generalist caterpillar Spodoptera littoralis is very efficient in excreting PAs. Senecionine $\mathrm{N}$-oxide was easily 
reduced to the tertiary alkaloids in the gut of S. littoralis, passively absorbed in the haemolymph and then quickly excreted (Lindigkeit et al. 1997). Other generalist insect species may be less efficient in excreting PAs and suffer similar mutagenic effects of PAs as Drosophila, but there are no data to support this yet.

Effects of PAs on generalist preference and performance

PAs can deter generalist insects (Bentley et al. 1984; Dreyer et al. 1985; Van Dam et al. 1995; Hägele and Rowell-Rahier 2000; Macel et al. 2005). In choice tests using artificial substrates such as lettuce disks or artificial diets, some but not all generalist herbivores avoided the PA-containing substrates. For example, larvae of the cabbage moth Mamestra brassicae were not deterred by PAs in artificial diets (Macel et al. 2005). On the other hand, all tested PAs deterred feeding of the migratory locust Locusta migratoria. Interestingly, when given the choice between senecionine and seneciphylline, the locusts preferred senecionine. This indicates that some PAs may be more deterrent than others (Macel et al. 2005). Similarly, the pea aphid Acyrthosiphon pisum was also more deterred by seneciphylline than by senecionine (Dreyer et al. 1985). Two stereo-isomers differed in their effects on spruce-budworm (Bentley et al. 1984) again indicating that small structural changes can affect the activity of PAs. Larvae of the noctuid Spodoptera exigua were only deterred by a mixture of senecionine type PAs and not by single PAs, indicating synergistic effects (Macel et al. 2005). In contrast, individual PAs of a different structural type (from Cynoglossum officinale) did deter feeding of S. exigua (Van Dam et al. 1995). The migratory locust was also more deterred by a mixture of PAs than individual alkaloids (Macel et al. 2005). The PA $N$-oxides are generally less deterrent than the tertiary PAs (Dreyer et al. 1985; Van Dam et al. 1995; Macel et al. 2005).

In plants, generalist insects usually prefer feeding on old leaves of Senecio rather than younger leaves (Van Dam et al. 1995; De Boer 1999). These younger leaves have higher PA concentrations than the older leaves (De Boer 1999). The amount of damage by the generalist thrips Frankliniella occidentalis was negatively correlated with PA concentrations in the leaves of S. jacobaea (Macel 2003). Optimal defense theory predicts that these most valuable plant parts should be better protected against herbivory (Zangerl and Bazzaz 1992; Van Dam et al. 1996). In the case of Senecio this seems certainly the case, young leaves and also the inflorescences have relatively high concentrations of alkaloids (Hartmann and Zimmer 1986; De Boer 1999).

Direct effects of PAs on the performance of generalist insect herbivores can be tested using artificial diets with and without alkaloids. Senecionine $\mathrm{N}$-oxide strongly decreased the survival of larvae of the eri silk moth Philosamia ricini (Saturniidae) (Narberhaus et al. 2005). Survival of the generalist aphid Myzus persicae was strongly affected by some PAs while other structurally related PAs had no effect (Macel et al. 2005). Thrips (F. occidentalis) survival was only affected by very high concentrations of PAs. The survival of the thrips on a diet with the PA retrorsine $N$-oxide was significantly higher than on the diet with the tertiary retrorsine (Macel et al. 2005). Interestingly the PA that had no effect on the aphid, senkirkine, had the strongest negative effect on the thrips (Macel et al. 2005). Such specific differences in effects between herbivores could lead to differential selection pressure on PAs in the field where herbivore presence and abundance shows spatiotemporal variation. Ultimately, this could contribute to the evolution of the diversity of these metabolites.

While bioassays with artificial diets clearly show an effect of PAs on the performance of some generalist insects, the relationship between PAs and generalist insect performance in plants is not always apparent and not well studied. In the field, the growth rate of the generalist aphid Brachycaudus cardii was negatively correlated with PAs of $S$. jacobaea (Vrieling et al. 1991a). In the greenhouse, population growth rate of the peach aphid Myzus persicae was extremely poor on $S$. jacobaea plants, but there was no correlation between PA concentration and aphid population growth (Macel 2003). The survival of larvae of $M$. brassicae was not correlated with PA concentration in host plants (Joshi and Vrieling 2005). It is likely that other factors besides PAs also determine performance of generalist herbivores on Senecio plants. Such factors could be other chemicals like sesquiterpenoids, nitrogen and sugars. Metabolomics, the untargeted screening of many metabolites of different classes, could shed light on all the 
(combinations of) compounds involved in host plant resistance. Using such a metabolomics approach $\left({ }^{1} \mathrm{H}-\mathrm{NMR}\right)$, Leiss et al. (2009) showed that thrips resistance in Senecio hybrids was amongst others related to the concentration of the PA jacobine $\mathrm{N}$-oxide but also to the flavonoid kaempferol.

\section{Specialist-generalist dilemma}

Natural plant populations often show genetic variation in levels of defense chemistry (Denno and McClure 1983; Mauricio and Rausher 1997). Van der Meijden (1996) proposed that the contrasting effects of plant secondary compounds on specialist vs. generalist insect herbivores would maintain this genetic variation in concentration of plant defense compounds. While generalists can be deterred by high levels of defense compounds, specialists may be attracted by the same compounds. Specialists also have evolved efficient adaptations to cope with the toxin in their hosts. The herbivore community in a plant population is likely to show spatial and temporal variation (Van der Meijden and Van Wijk 1997). The abundance of specialists vs. generalists, for example, will shift through time. Therefore, the direction of selection on plant defense will shift accordingly. An example of opposing selection on a defense trait is the contrasting selection imposed on sinigrin (glucosinolate) levels in Brassica nigra by a specialist aphid and generalist snails and slugs (Lankau 2007). By manipulating the herbivores in the field (removing either the specialists or the generalists), it was shown that in the presence of specialists there was selection for low levels of sinigrin, with generalists there was selection for high levels of sinigrin and when both generalist and specialist herbivores present selection was neutral.

In natural Senecio populations there is often considerable genetic variation in PA concentrations and profiles (Vrieling et al. 1993). Although not explicitly tested, it is likely that fluctuating ratios of generalist vs. specialist in the field will cause shifting selection pressure on PAs and thus could maintain the genetic variation in PA concentration. As I outlined earlier, studies have shown that specialists on Senecio are generally well adapted to the PAs in their host plant and can use these compounds as host finding cue. Generalists on the other hand may be deterred by PAs. In a field experiment using different $S$. jacobaea clones, there was little damage to the plants in the site with mainly generalist herbivores, while in the site that harbored also specialist herbivores damage was considerable. At the site with specialist herbivores, PA concentration and damage were positively correlated, but there was no correlation between plant damage and PA concentration at the generalist site (Macel and Klinkhamer 2010). The question is whether these correlations between PAs and damage lead to a fitness effect in Senecio plants. Only then, the strength of the selection by herbivores on PAs can be determined.

In addition to the specialist-generalist dilemma, a plant is also faced with the dilemma of the different sensitivity of herbivores towards individual PAs. While alkaloid $\mathrm{X}$ can act as defense towards insects species A, alkaloid Y may act as a better defense against insect species $\mathrm{B}$, as was shown for the contrasting effects of the PAs senecionine and senkirkine on thrips and aphids (Macel et al. 2005). Such opposing selection pressures of different herbivores could explain the maintenance of the diversity of PAs found in Senecio species (Witte et al. 1992). It is also thought that the ongoing evolutionary armsrace between plants and herbivores has led to the diversity of plant chemical compounds (Ehrlich And Raven 1964). The differences in activity of closely related PAs to insect herbivores indicate that small structural changes can turn PAs more or less effective as defense chemicals. Finally, the diversity of PAs in Senecio could also be maintained through synergistic effects of PAs on generalist herbivores. Of course, other factors such as defense against fungi (Hol and Van Veen 2002) or effects of PAs on higher trophic levels (Vrieling et al. 1991b) can also play a role in the evolution and maintenance of the diversity of PAs. Thus far, allocation costs of producing PAs have not been detected (Vrieling and van Wijk 1994). It is also possible that the diversity of PAs is selectively neutral, if the production of various PAs within a single plant does not lead to extra costs (Jones and Firn 1991). However, as outlined in this review, PAs can differ in their ecological costs and benefits towards insect herbivores. Insect herbivores may thus contribute to the evolution and maintenance of the diversity of secondary compounds such as PAs. 
Acknowledgments I would like to thank Eddy van der Meijden, Peter Klinkhamer, Klaas Vrieling and all other members of the IBL plant ecology group for their support and stimulating discussions. This is publication 4752 of the Netherlands Institute of Ecology (NIOO-KNAW).

Open Access This article is distributed under the terms of the Creative Commons Attribution Noncommercial License which permits any noncommercial use, distribution, and reproduction in any medium, provided the original author(s) and source are credited.

\section{References}

Aplin RT, Rotschild M (1972) Poisonous alkaloids in the body tissues of the garden tiger moth (Arctia caja L.) and the cinnabar moth (Tyria $(=$ Callimorpha $)$ jacobaeae L.) (Lepidoptera). In: De Vries A, Kochva E (eds) Toxins of animal and plant origin, vol 2. Gordon and Breach Sci Pub, New York, pp 579-595

Bentley MD, Leonard DE, Stoddard WF et al (1984) Pyrrolizidine alkaloids as larval feeding deterrents for spruce budworm, Choristoneura fumiferana (Lepidoptera: Tortricidae). Ann Entomol Soc Am 77:393-397

Bernays EA, Chapman RF, Hartmann T (2002a) A highly sensitive taste receptor cell for pyrrolizidine alkaloids in the lateral galeal sensillum of a polyphagous caterpillar, Estigmene acrea. J Comp Physiol A 188:715-723

Bernays EA, Chapman RF, Hartmann T (2002b) A taste receptor neurone dedicated to the perception of pyrrolizidine alkaloids in the medial galeal sensillum of two polyphagous arctiid caterpillars. Physiol Entomol 27:312-321

Bernays EA, Chapman RF, LaMunyon CW et al (2003) Taste receptors for pyrrolizidine alkaloids in a monophagous caterpillar. J Chem Ecol 29:1709-1722

Bernays EA, Hartmann T, Chapman RF (2004) Gustatory responsiveness to pyrrolizidine alkaloids in the Senecio specialist, Tyria jacobaeae (Lepidoptera, Arctiidae). Physiol Entomol 29:67-72

Boppré M (1986) Insects pharmacophagously utilizing defensive plant chemicals (pyrrolizidine alkaloids). Naturwissenschaften 73:17-26

Cheeke PR (1988) Toxicity and metabolism of pyrrolizidine alkaloids. J Anim Sci 66:2343-2350

De Boer NJ (1999) Pyrrolizidine alkaloid distribution in Senecio jacobaea rosettes minimises losses to generalist feeding. Entomol Exp Appl 91:169-173

Denno RF, McClure MS (1983) Variable plants and herbivores in natural and managed systems. Academic Press, New York

Deprés L, Davis J, Gallet C (2007) The evolutionary ecology of insect resistance to plant chemicals. Trends Ecol Evol 22:298-307

Dobler S (2001) Evolutionary aspects of defense by recycled plant compounds. Basic Appl Ecol 2:15-26

Dreyer DL, Jones KC, Molyneux RJ (1985) Feeding deterrency of some pyrrolizidine, indolizidine, and quinolizidine alkaloids towards pea aphid (Acyrthosiphon pisum) and evidence for phloem transport of indolizidine alkaloid swaisonine. J Chem Ecol 11:1045-1051
Ehmke A, Witte L, Biller A et al (1990) Sequestration, N-oxidation and transformation of plant pyrrolizidine alkaloids by the arctiid moth Tyria jacobaeae. Z Naturforsch 45c:1185-1192

Ehrlich PR, Raven PH (1964) Butterflies and plants: a study in coevolution. Evolution 18:586-608

Eisner T, Eisner M (1991) Unpalatability of pyrrolizidine alkaloid containing moth Utheteisa ornatrix, and its larva, to wolfspiders. Psyche 98:11-118

Frei H, Lüthy J, Brauchli J et al (1992) Structure/activity relationships of the genotoxic potencies of sixteen pyrrolizidine alkaloids assayed for the induction of somatic mutation and recombination in wing cells of Drosophila melanogaster. Chem Biol Interact 83:1-22

Hägele BF, Rowell-Rahier M (2000) Choice, performance and heritability of performance of specialist and generalist insect herbivores towards cacalol and seneciphylline, two allelochemicals of Adenostyles alpina (Asteraceae). J Evol Biol 13:131-142

Harper JL, Wood WA (1957) Senecio jacobaea L. J Ecol 45:617-637

Hartmann T (1999) The chemical ecology of pyrrolizidine alkaloids. Planta 207:483-495

Hartmann T, Dierich B (1998) Chemical diversity and variation of pyrrolizidine alkaloids of the senecionine type: biological need or coincidence? Planta 206:443-451

Hartmann T, Witte L (1995) Chemistry, biology and chemoecology of the pyrrolizidine alkaloids. In: Pelletier SW (ed) Alkaloids: chemical and biological perspectives, vol 9. Pergamon Press Elmsford, New York, pp 156-233

Hartmann T, Zimmer M (1986) Organ-specific distribution and accumulation of pyrrolizidine alkaloids during the life history of two annual Senecio species. J Plant Physiol 122:67-80

Hol WHG, Van Veen JA (2002) Pyrrolizidine alkaloids from Senecio jacobaea affect fungal growth. J Chem Ecol 28:1763-1772

Hol WHG, Macel M, Van der Meijden E, Van Veen JA (2004) Root damage and aboveground herbivory change concentration and composition of pyrrolizidine alkaloids in Senecio jacobaea. Basic Appl Ecol 3:253-260

Honda K, Hayashi N, Abe F et al (1997) Pyrrolizidine alkaloids mediate host-plant recognition by ovipositing females of an old world danaid butterfly, Idea leuconoe. J Chem Ecol 23:1703-1713

Jones CG, Firn RD (1991) On the evolution of plant secondary chemical diversity. Proc R Soc B: Biol Sci 333:273-280

Joosten L, Mulder PPJ, Klinkerhamer PGL, Van Veen JA (2009) Soil-borne microorganisms and soil-type affect pyrrolizidine alkaloids in Jacobaea vulgaris. Plant Soil 325:133-143

Joshi J, Vrieling K (2005) The enemy release and EICA hypothesis revisited: incorporating the fundamental difference between specialist and generalist herbivores. Ecol Lett 8:704-714

Kelley CK, Johnson KS, Murray M (2002) Temporal modulation of pyrrolizidine alkaloid intake and genetic variation in performance of Utetheisa ornatrix caterpillars. J Chem Ecol 28:669-685

Lankau RA (2007) Specialist and generalist herbivores exert opposing selection on a chemical defense. New Phytol 175:176-184 
Leiss KA, Choi YH, Abdel-Farid IB et al (2009) NMR metabolomics of thrips (Frankliniella occidentalis) resistance in Senecio hybrids. J Chem Ecol 35:219-229

Li W, Schuler MA, Berenbaum MR (2003) Diversification of furanocoumarin-metabolizing cytochrome P450 monoxygenase in two papilionids: specificity and substrate encounter rate. Proc Natl Acad Sci USA 100:14593-14598

Lindigkeit R, Biller A, Buch M et al (1997) The two faces of pyrrolizidine alkaloids: the role of tertiary amine and its $\mathrm{N}$-oxide in chemical defense of insects with acquired plant alkaloids. Eur J Biochem 245:626-636

Macel M (2003) On the evolution of the diversity of pyrrolizidine alkaloids: the role of insects as selective forces. PhD Thesis, Leiden University, The Netherlands

Macel M, Klinkhamer PGL (2010) Chemotype of Senecio jacobaea affects damage by herbivores and pathogens in the field. Ecol Evol (in press)

Macel M, Vrieling K (2003) Pyrrolizidine alkaloids as oviposition stimulants for the cinnabar moth Tyria jacobaeae. $\mathrm{J}$ Chem Ecol 29:1435-1446

Macel M, Klinkhamer PGL, Vrieling K et al (2002) Diversity of pyrrolizidine alkaloids in Senecio species does not affect the specialist herbivore Tyria jacobaeae. Oecologia 133:541-550

Macel M, Bruinsma M, Dijkstra SM et al (2005) Differences in effects of pyrrolizidine alkaloids on five generalist insect herbivore species. J Chem Ecol 31:1493-1508

Mattocks AR (1986) Toxicity of pyrrolizidine alkaloids. Nature 217:723-728

Mauricio R, Rausher MD (1997) Experimental manipulation of putative selection agents provides evidence for the role of natural enemies in the evolution of plant defense. Evolution 51:1435-1444

Naberhaus I, Theuring C, Hartmann T et al (2003) Uptake and metabolism of pyrrolizidine alkaloids in Longitarsus flea beetles (Coleoptera: Chrysomelidae) adapted and nonadapted to alkaloid containing host plants. J Comp Physiol B 173:483-491

Narberhaus I, Zintgraf V, Dobler S (2005) Pyrrolizidine alkaloids on three trophic levels-evidence for toxic and deterrent effect on phytophages and predators. Chemoecology 15:121-125

Naumann C, Hartmann T, Ober D (2002) Evolutionary recruitment of a flavin-dependent monooxygenase for the detoxification of host plant-acquired pyrrolizidine alkaloids in the alkaloid-defended arctiid moth Tyria jacobaeae. Proc Natl Acad Sci USA 99:6085-6090

Nishida R (2002) Sequestration of defensive substances from plants by Lepidoptera. Annu Rev Entomol 47:57-92

Pasteels JM, Theuring C, Witte L et al (2003) Sequestration and metabolism of protoxic pyrrolizidine alkaloids by larvae of the leaf beetle Platyphora boucardi and their transfer via pupae into defensive secretions of adults. J Chem Ecol 29:337-355

Rothschild M, Aplin RT, Cockrum PA et al (1979) Pyrrolizidine alkaloids in arctiid moths (Lep.) with a discussion on host plant relationships and the role of these secondary plant substances in the Arctiidae. Biol J Linn Soc 12:305-326

Stastny M, Schaffner U, Elle E (2005) Do vigour of introduced populations and escape from specialist herbivores contribute to invasiveness? J Ecol 93:27-37
Van Dam NM, Van der Meijden E, Verpoorte R (1993) Induced responses in three alkaloid-containing plant species. Oecologia 95:425-430

Van Dam NM, Vuister LWN, Bergshoeff C et al (1995) The 'raison d'être' of pyrrolizidine alkaloids in Cynoglossum officinale: deterrent effects against generalist herbivores. J Chem Ecol 21:507-523

Van Dam NM, de Jong TJ, Iwasa Y et al (1996) Optimal distribution of defenses: are plants smart investors? Funct Ecol 10:128-136

Van der Meijden E (1996) Plant defence, an evolutionary dilemma: contrasting effects of (specialist and generalist) herbivores and natural enemies. Entomol Exp Appl 80:307-310

Van der Meijden E, van Wijk C (1997) Tritrophic metapopulation dynamics. A case study of ragwort, the cinnabar moth and the parasitoid Cotesia popularis. In: Hanski IA, Gilpin ME (eds) Metapopulation biology. Ecology, genetics and evolution. Academic Press, San Diego, pp 387-405

Van der Meijden E, Van Zoelen AM, Soldaat LL (1989) Oviposition by the cinnabar moth, Tyria jacobaeae, in relation to nitrogen, sugars and alkaloids of ragwort, Senecio jacobaea. Oikos 54:337-344

Van Zoelen A, Van der Meijden E (1991) Alkaloid concentration of different developmental stages of the cinnabar moth (Tyria jacobaeae). Entomol Exp Appl 61:291-294

Von Nickisch-Rosenegk E, Wink M (1993) Sequestration of pyrrolizidine alkaloids in several arctiid moths (Lepidoptera: Arctiidae). J Chem Ecol 19:1889-1903

Vrieling K, de Boer NJ (1999) Host plant choice and larval growth in the cinnabar moth: do pyrrolizidine alkaloids play a role? Entomol Exp Appl 91:251-257

Vrieling K, van Wijk CAM (1994) Estimating costs and benefits of the pyrrolizidine alkaloids of Senecio jacobaea under natural conditions. Oikos 70:449-454

Vrieling K, Soldaat LL, Smit W (1991a) The influence of pyrrolizidine alkaloids of Senecio jacobaea on Tyria jacobaeae, Brachycaudus cardii and Haplothrips senecionis. Neth J Zool 41:228-239

Vrieling K, Smit W, Van der Meijden E (1991b) Tritrophic interactions between aphids (Aphis jacobaeae Schrank), ant species, Tyria jacobaeae L. and Senecio jacobaea L. lead to maintenance of genetic variation in pyrrolizidine alkaloid concentration. Oecologia 86:177-182

Vrieling K, de Vos H, van Wijk CAM (1993) Genetic analysis of the concentration of pyrrolizidine alkaloids of Senecio jacobaea. Phytochemistry 32:1141-1144

Wink M, Schmeller T, Latz-Brüning B (1998) Modes of action of allelochemical alkaloids: interaction with neuroreceptors, DNA, and other molecular targets. J Chem Ecol 24:1881-1909

Witte L, Ernst L, Adam H, Hartmann T (1992) Chemotypes of two pyrrolizidine alkaloid-containing Senecio species. Phytochemistry 31:559-565

Wittstock U, Agerbirk N, Stauber EJ et al (2004) Successful herbivore attack due to metabolic diversion of a plant chemical defense. Proc Natl Acad Sci USA 14:4859-4864

Zangerl AR, Bazzaz FA (1992) Theory and pattern in plant defense allocation. In: Fritz RS, Simms EL (eds) Plant resistance to herbivores and pathogens. University of Chicago Press, Chicago, pp 363-391 